\title{
A INQUIETANTE ARQUITETURA
}

\author{
Reinaldo Guedes Machado ${ }^{12}$
}

\section{Resumo}

$\mathrm{O}$ artigo toma a sugestão feita por Freud de pensar o Inquietante como categoria de estética e busca reconhecer no cinema expressionista alemão e no prédio do Jüdisches Museum Berlin (Museu Judaico de Berlim) a realização sensível do conceito estabelecido no texto freudiano.

Palavras-chaves: Inquietante, Expressionismo, Museu, Judaísmo, Libeskind.

\begin{abstract}
This paper takes the suggestion of Freud to think the Uncanny as an aesthetic category and attempts to recognize in German expressionist cinema and in Jüdisches Museum Berlin (Jewish Museum Berlin) building the sensitive realization of the concept settled in Freud's text.
\end{abstract}

Keywords: Uncanny, Expressionism, Museum, Judaism, Libeskind.

\footnotetext{
${ }^{1}$ Reinaldo Guedes Machado possui graduação em Arquitetura e Urbanismo pela Universidade Federal de Pernambuco (1972) e doutorado em Arquitetura e Urbanismo pela Universidade de São Paulo (2003). Atualmente é professor adjunto da Universidade de Brasília.

${ }^{2}$ Fotos: Alexandre Pereira Magalhães, Dr. Rodrigo de Faria e de Reinaldo Guedes Machado.
} 
Em 1919, Sigmund Freud publicou Das Unheimliche, um curto artigo no qual considera desenvolver um tema próprio da estética, quando por estética se entende não simplesmente a teoria da beleza, mas a teoria das qualidades do sentir. (Freud,1996, p.237). Para isso, analisa os procedimentos adotados por poetas e contistas para despertar a sensação de estranheza ou inquietação no leitor ao mesmo tempo em que investiga os processos psicológicos acionados na sensação de inquietude provocada pela literatura ou por acontecimentos na vida real.

A tradução do referido texto freudiano para o português apresenta uma dificuldade particular. Na língua alemã o conceito central ali tratado, das Unheimliche, contem em si o seu contrário, Heimliche, isto é, aquilo que é familiar, conhecido, íntimo e também o que é secreto, tratado em segredo por um pequeno grupo, aquilo que não se deve publicar ou dar a conhecer.

Assim, Unheimliche designa não só o que não é familiar, mas também aquilo que sendo estranho contem, contudo, algo conhecido embora sob forma velada. Tal não se dá com a palavra "estranho" pela qual Eudoro Augusto Maciel da Silveira a traduziu, comentando em nota de rodapé a imprecisão do termo português e justificando sua escolha "por ser talvez o único [adjetivo da língua portuguesa] capaz de combinar as conotações da área semântica de 'fantástico', 'misterioso', 'sinistro' - ' (Freud,1996, p.237)

O tradutor Paulo Cesar de Souza optou pela expressão $O$ inquietante (Freud, 2010) que, embora se afaste da tradução literal, adequa-se admiravelmente ao tema tratado pois no texto em consideração Freud não se ocupou da curiosidade, do interesse ou mesmo entusiasmo que o estranho, o desconhecido ou a novidade podem despertar; ou seja, não se ocupou das formas de inquietação prazerosas; pelo contrário limitou o seu estudo aos sentimentos de medo, de insegurança, de desorientação que o estranho pode provocar.

Para o psicanalista, o desconforto dos sentimentos associados à inquietação, numa gama que vai da estranheza ao terror, são resultantes do retorno de conteúdos emocionais recalcados ao esquecimento como resultado do esforço do ego em desenvolvimento visando compatibilizar as exigências dos impulsos mais primitivos e as limitações impostas pela realidade.

Na infância, quando ainda se é inevitavelmente dependente do cuidado dos adultos, vive-se o medo do silêncio, do escuro e da solidão/abandono; o medo da "onipotência do 
pensamento" suposto como capaz de produzir magicamente efeito no mundo real cujas consequências negativas talvez atinjam o pensador; o medo de conhecer o que deve permanecer oculto; medo da castração ou mutilação como castigo pelo desejo incestuoso; o medo dos poderes misteriosos impregnados em determinados objetos e lugares, medo da morte que será mais tarde abrandado pela ideia da alma, o duplo imortal do vivo, mas cujo destino é incerto ainda que a fé religiosa possa anunciar recompensas a uma vida virtuosa.

As pequenas superstições, "simpatias" e a indagação da mensagem oculta numa série de coincidências, a que ocasionalmente todos nós nos entregamos, atestam a permanência inconsciente de resíduos da crença animista e na magia e dos medos aparentemente e superados na idade adulta. Assim, acontecimentos, lugares, sons e formas têm o poder de evocar, por semelhança, a carga emocional vivenciada em períodos anteriores ao amadurecimento do ego.

O material em que Freud apoia suas reflexões são experiências pessoais, relatos de pacientes e a literatura alemã. O conto $O$ Homem de areia de E.T. Hoffman é resenhado por ele e estudado em profundidade. O personagem central, Nataniel pensa reconhecer no vendedor de instrumentos ópticos, Giuseppe Coppola, o advogado Copélio, que frequentava sua casa na infância, e que então identificara como o Homem de Areia, personagem fantástica que roubava os olhos dos meninos desobedientes, segundo as ameaças de sua babá. O poder maléfico do advogado pareceu confirma-se quando numa de suas visitas uma explosão no escritório mata o pai da criança.

Apesar do desconforto desse reencontro que fizera emergir suas crenças e emoções infantis, Nataniel compra ao vendedor, de duvidosa identificação, uma luneta com a qual passa a observar a casa em frente a sua, e confunde uma boneca autômato em construção pelo dono da casa com a filha deste. Pela luneta, vê horrorizado, Coppola/Copélio, retirar os olhos de vidro da boneca para talvez substituí-los. Sob o impacto da cena mal compreendida, Nataniel enlouquece de terror.

Freud infere como causa do terror de Nataniel o retorno do afeto recalcado despertado pela ambiguidade inicial do reencontro e a confirmação posterior de que Copélio e Coppola são a mesma pessoa; o temor infantil de castração simbolizado pelos olhos arrancados da boneca confundida com a moça.

A passagem da teoria psicanalítica ao terreno da estética se fará em Das Unheimliche quando, Freud procurar elucidar quais os procedimentos de construção do conto conduzem o 
leitor a sentir-se no mesmo clima sombrio, no mesmo estado de inquietude do personagem, depois de descrever os processos psicológicos envolvidos nas sensações de estranheza, de incerteza na interpretação da realidade e do medo vivido pelo personagem de Hoffman, por ele mesmo e por seus pacientes,

Freud considerava as artes e a literatura como representação válida do comportamento e da psique humana. Apoiou-se nos clássicos gregos, em Shakespeare, em Goethe e até em escritores seus contemporâneos para argumentar em defesa da construção teórica que elaborava ou para corrigi-la quando necessário. Também se valeu do estudo das obras de Leonardo da Vinci e Michael Ângelo Buonarotti, do Moisés de pedra e do personagem bíblico, fundador do judaísmo, para compreensão da psique individual e coletiva.

Curiosamente porém não deu atenção ao cinema expressionista alemão que no mesmo ano em que ele escrevia Das Unheimliche instituía o inquietante como categoria estética reconhecida pelo público e aplaudida em filmes de ampla aceitação como $O$ gabinete de $\mathrm{Dr}$. Caligari (Wienne, 1920) ${ }^{3}$ lançado em 1920. Mas não só o cinema, também as artes plásticas tomavam por tema de interesse nos respectivos campos os sentimentos de apreensão, medo e incerteza disseminados na Alemanha e na Áustria após derrota na guerra de 1914-17. ${ }^{4}$

O cinema, essa arte híbrida, traduzia essa angústia em imagens visuais; o naturalismo fotográfico foi abandonado para que os cenários e roupas, a iluminação, a expressão corporal dos atores, fossem dirigidos a obter uma representação sensível do mundo assustador que o roteiro apresentava. A pintura e o cinema expressionista, rejeitaram as composições referenciadas a eixos ordenadores verticais ou horizontais assim como desprezaram as regras da perspectiva renascentista que nos localizam com precisão no espaço real ou imaginário. A arquitetura dentro desses filmes é distorcida, a verga superior das portas e janelas é dramaticamente inclinada e é quase sempre mais larga do que a soleira mesmo quando são vistos pela câmara baixa, invertendo-se por meio da pintura e marcenaria a perspectiva que seria captada pela câmera. A luminosidade da cena não se define só pelos recursos de iluminação empregados, aliás limitados pelas técnicas da época, mas recorre a vigorosos contrastes de negro e luz pintados nas paredes e piso do cenário.

\footnotetext{
3 WIENNE, Robert, Das Cabinet des Dr. Caligari, Berlim: DECLA Film Gesellchaft1920 Disponível em <https://www.youtube.com/watch?v=AP3WDQXkJq4>

$4 \mathrm{O}$ fenômeno por certo refletia a angustia que pairava sobre o povo alemão após a derrota na primeira grande guerra (1914-1917). A certeza de suas potencialidades como nação, a grandeza e a arrogância do Império desabara humilhada pelas imposições dos vencedores, pobreza e desemprego se alastravam enquanto a nação pagava pesadas indenizações financeiras pelos danos da guerra aos países agredidos
} 
Assim é em $O$ gabinete de Dr. Caligari, o filme inaugural do cinema expressionista alemão lançado no mesmo ano da publicação de Das Heimliche, o qual talvez possa servir de reforço às observações de Freud sobre os elementos capazes de produzir o sentimento de inquietação face a uma situação ou obra de arte, apesar da diferença entre as fontes materiais do estudo: literatura e relatos pessoais no primeiro caso e o cinema e cenografia, no segundo.
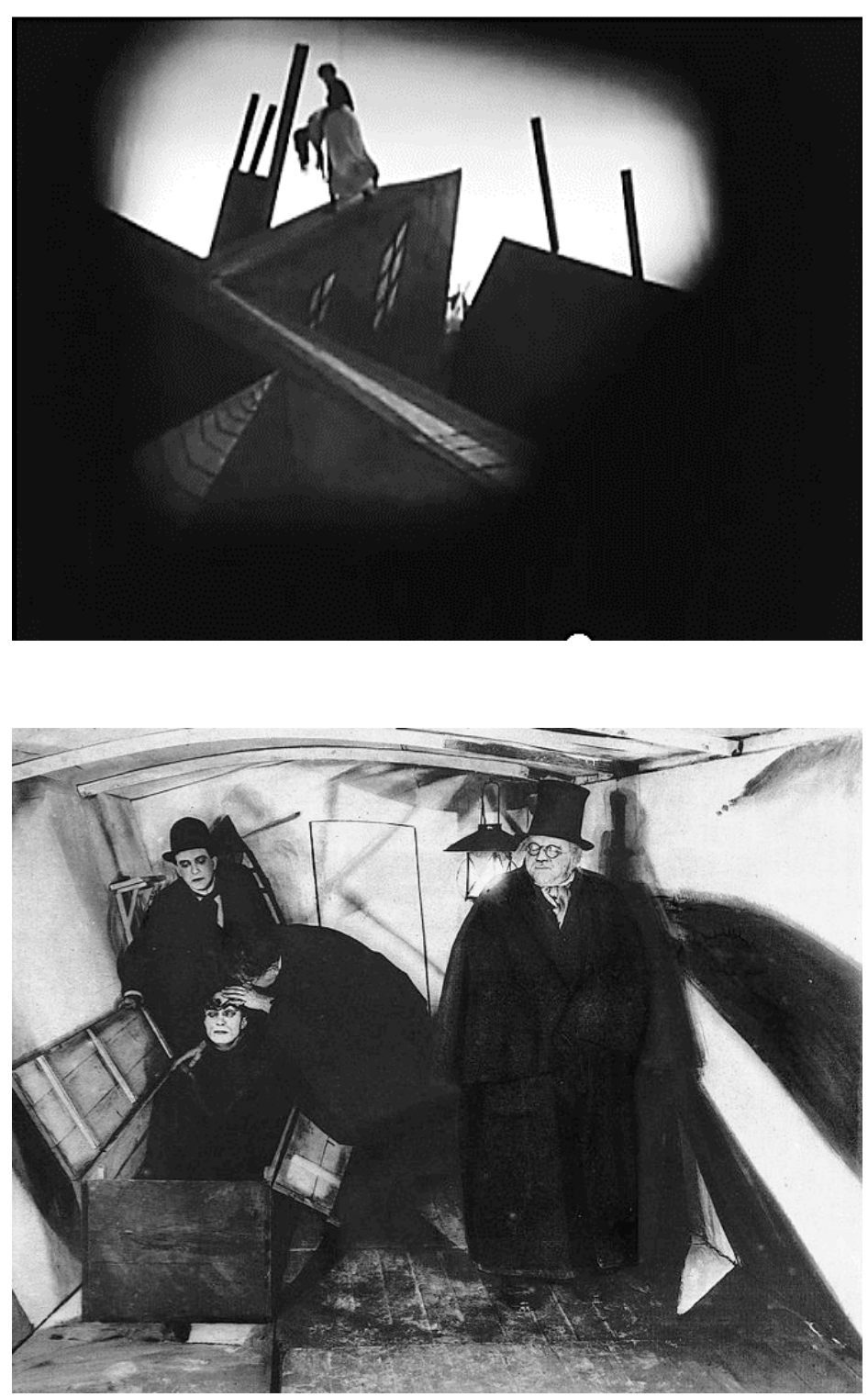


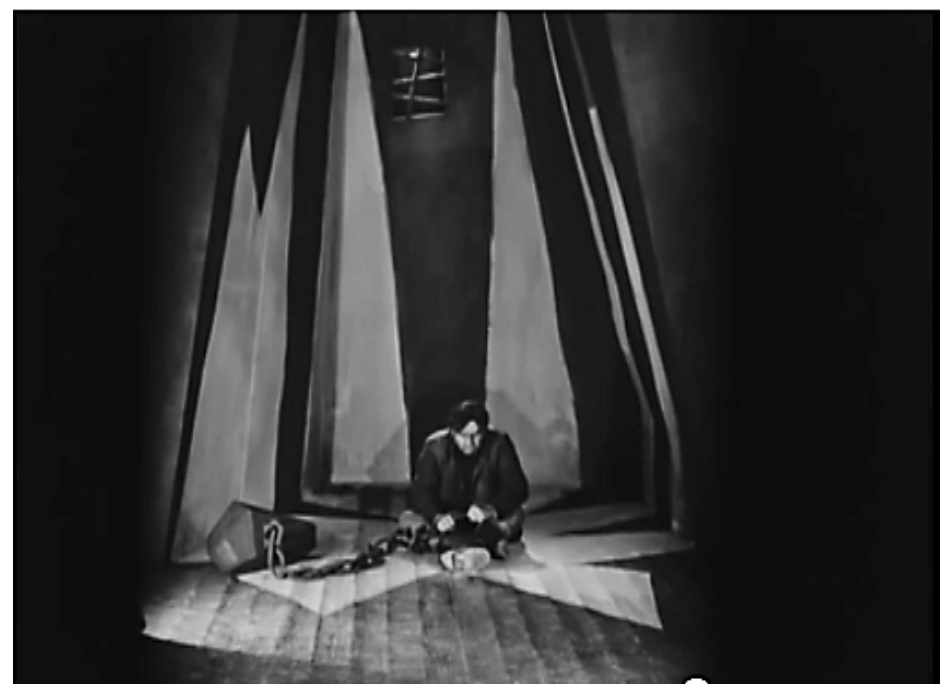

Fig. 1, 2 e 3: Fotogramas de $O$ Gabinete do Dr. Caligari.

Fonte: https://www.youtube.com/watch?v=gkWdNeZnBCA

No campo da arquitetura efetivamente edificada, uma obra de qualidade excepcional retoma alguns dos recursos plásticos do cinema expressionista alemão senão para provocar o medo dos filmes de terror, ao menos para evocar a inquietude, e o desconforto de reconhecer a insanidade que pôde irromper inesperadamente numa civilização cultora da razão, da eficiência e da produtividade.

Trata-se do Museu Judaico de Berlim, inaugurado em 2001, o qual amplia a gama dos modos de sentir ligados à categoria do Inquietante além dos sentimentos medo e terror já explorados na literatura romântica e no cinema expressionista. Acrescenta-lhes o sentimento de desconforto trazido pela evocação de momentos traumáticos na história do século $\mathrm{XX}$, quando a civilização ocidental como que regrediu à barbárie apesar de toda riqueza e conhecimentos acumulados por séculos de culto a razão, ao direito e a beleza.

Há perfeita adequação entre a forma arquitetônica do museu e os objetivos pelos quais foi construído, quais sejam: apresentar a história dos judeus na Alemanha desde a antiguidade romana aos dias presentes e manter visível a memória do holocausto.

O prédio e seu acervo são indissociáveis, a arquitetura evoca os acontecimentos que o museu pretende rememorar pelos meios próprios dessa arte, tais como a articulação e o dimensionamento dos espaços, padrões de iluminação, volumetria e tratamento das fachadas, etc. 


\title{
O MUSEU JUDAICO DE BERLIM
}

\begin{abstract}
Aqueles não são espaços livres: são espaços profundamente ideológicos. Acredito que o 'espaço' possui uma capacidade própria para ser autêntico. E isso se manifestará através da experiência que ele puder provocar. Sim, eu usei de fato os meios arquitetônicos possíveis - materiais, proporção, luz - tudo aquilo que compõe uma arquitetura tradicional, a fim de criar um espaço que nunca havia existido antes. Por que jamais houve um edifício cuja entrada é pelo prédio barroco ao lado; onde você desce 12 metros em direção às fundações e que possui escadas e circulações que são completamente inusitadas em relação àquilo que qualquer pessoa esperaria de um museu... tudo isso é parte de um mergulho no qual pretendi lançar o visitante, tendo por objetivo que ele experiencie o que viveram os judeus em Berlim. (LIBESKIND, 2000) $)^{5}$.
\end{abstract}

Dois prédios compõem o novo Jüdisches Museum Berlin: um pequeno palácio rococó que sediou outrora a Suprema Corte do Reino da Prússia e uma nova construção de aspecto industrial revestida de zinco (Fig. 5,6,7 e 8).

Não são porém dois edifícios de épocas diferentes colocados lado a lado pelas contingências do acaso. Pelo contrário, são partes de uma única concepção de arquitetura em que o velho prédio reforça a intenção e o significado do conjunto. De fato, a entrada ao museu é feita pelo edifício antigo reaproveitado como recepção, exposições temporárias e restaurante. Nele foi inserido um prisma de concreto que o atravessa do sótão ao subsolo como uma torre vazia não visível do exterior, e dentro dela, uma escada descendente leva ao corredor que liga os dois blocos do museu no subsolo. $\mathrm{O}$ aspecto agressivo das paredes brutas de concreto que transpassam ambientes delicados de um palácio da monarquia anuncia a estranheza do mundo em que vamos penetrar. Assim também essa insólita entrada descendente a inverter o padrão costumeiro da maioria dos museus, teatros e lugares de cultura, em que geralmente escadarias monumentais sobem do piso térreo aos andares superiores onde se localizam os ambientes principais das atividades a que se destina o edifício (Fig.4).

5 Libeskind apud MACHADO, Marisa F. Museu Judaico de Berlim - Daniel Libeskind. Disponível em $<$ https://fauforma2.files.wordpress.com/2009/08/libeskind_museu-judaico-de-berlim.pdf $>$ [Traz a tradução do depoimento do arquiteto em vídeo de NEUMANN, Stan e COPANS,Richard.Le mueée Juif de Berlin - Entre les lignes. Paris: Le Centre George Pompidou, 2000.] 


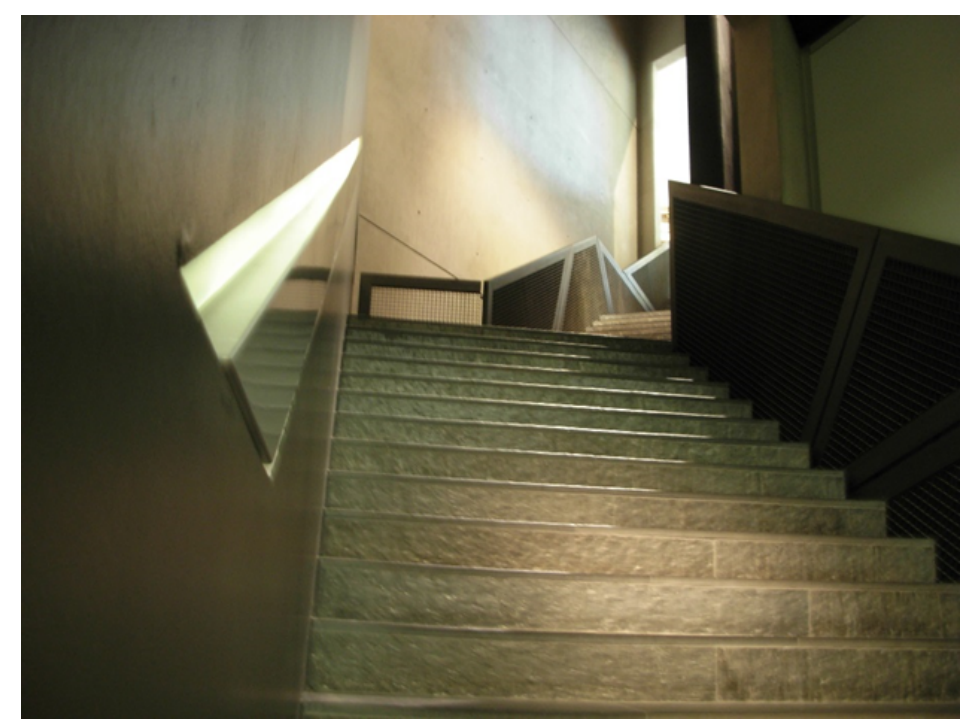

Fig.4: Escada inserida no prédio antigo que leva ao subsolo do novo bloco.

Foto: Reinaldo Guedes Machado.

O volume do novo prédio é dominante na composição. É uma longa caixa prismática erguida sobre uma planta em zig-zag, logo apelidado Blitz (relâmpago) pelos berlinenses. Tem fachadas revestidas de zinco, rasgadas por compridas frestas de vidro dispostas sem ordem aparente, cujo desenho de conjunto, embora pareça arbitrário, decorre da transposição ao plano vertical do diagrama traçado pelo arquiteto ao riscar sobre o mapa de Berlim ligações entre pontos onde residiram os mais conhecidos judeus da história da cidade.

O tratamento artesanal da fachada simétrica, coroada por frontão triangular com esculturas, do antigo tribunal, contraposto a aparência industrial do edifício revestido de metal e a pequena diferença de altura entre os dois blocos, assim como a distância correta guardada entre eles valorizam ambos e os integram a figurarem uma história contínua embora com bruscas mudanças de direção.
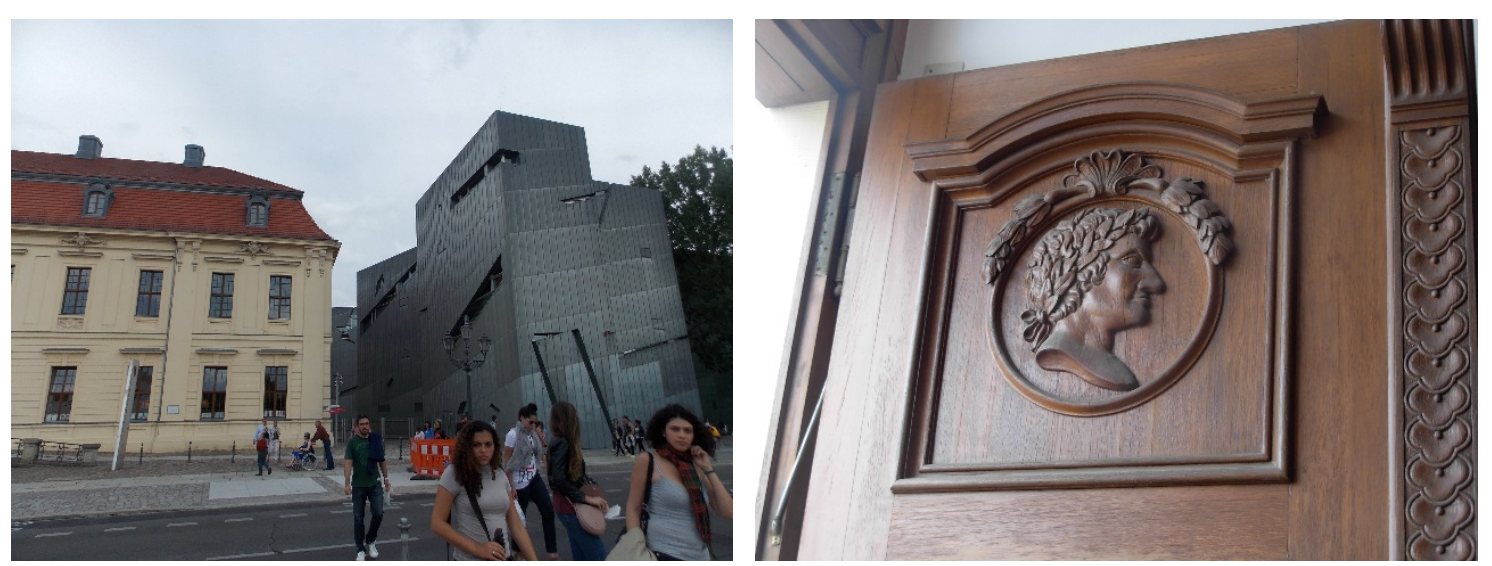

Fig. 5: Antiga sede da Suprema Corte da Prússia e a nova construção.

Foto: Dr. Rodrigo de Faria. 
Fig. 6: Porta de entrada da Suprema Corte do Reino da Prussia, atualmente Museu Judaico de Berlim. Foto: Reinaldo Guedes Machado.
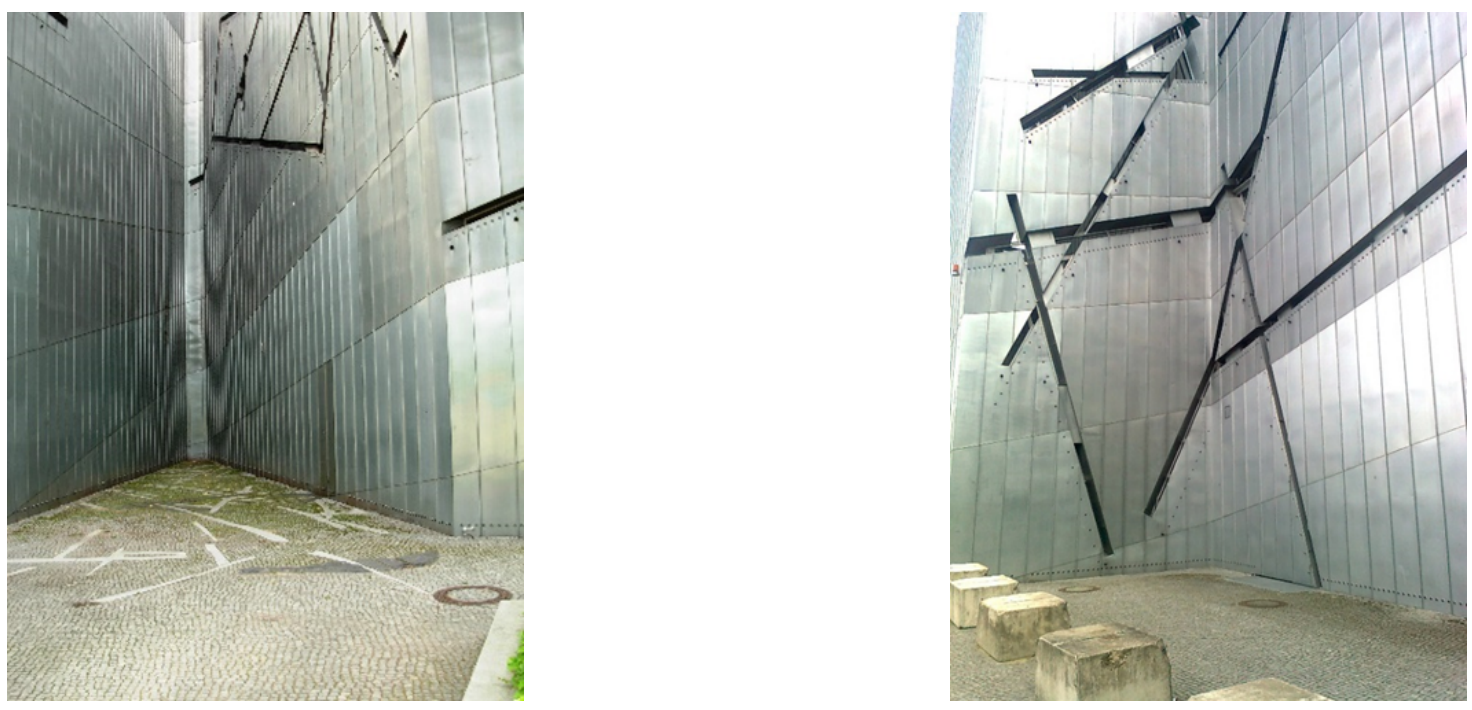

Fig.7: Bloco novo visto da rua, cantos mortos. Foto: Alexandre Pereira Magalhães.

Fig.8: Bloco novo visto da rua. Janelas, frestas. Foto: Reinaldo Guedes Machado.

\section{O BLOCO DAS SALAS DE EXPOSIÇÃO}

Este bloco novo é evidentemente centro vital do conjunto, onde o trabalho realizado pelos servidores do museu é comunicado ao público em geral. No pavimento mais alto ficam os escritórios e outras áreas de trabalho dos servidores do museu; abaixo deste, as áreas de acesso público, as salas de exposição.

A arquitetura de museus desde as últimas décadas do século $\mathrm{XX}$ vem se afastando dos princípios norteadores dos museus modernistas: ambientes neutros, salões como cubos brancos que interfiram o mínimo possível com a apreciação das obras expostas; percurso de visita definido no projeto e claramente reconhecível pelos visitantes, facilitando a montagem de exposições lineares como um texto escrito, organizadas ora por gêneros e técnicas, ora segundo um eixo cronológico. As exposições de implícito caráter didático, racional, classificatório, repassavam $o$ conhecimento, mas também o gosto e a ideologia dos museólogos e curadores valorizada pelo ambiente neutro, confortável e bem iluminado.

O prédio do Museu Judaico de Berlim não se pretende neutro, não é apenas o involucro que abriga em boas condições os objetos expostos, mas interfere, se 
pronuncia, evoca o clima de apreensão, maior ou menor conforme o lugar e a época, em que viveram os judeus na Alemanha. Paredes de concreto cinza, pés-direitos altos, visão do exterior limitada pelas janelas-frestas irregularmente distribuídas, colocam o visitante num espaço de recolhimento onde algo profundo, íntimo, lhe será comunicado sem sensacionalismo. Algo "Heimlich" na segunda conotação da palavra: aquilo que não deve ser vulgarizado, que é conhecido apenas por grupo especial, confiável, de amigos e familiares e, em alguns casos, de cumplices numa conspiração.

O visitante não é conduzido por um único percurso pré-definido pelo arquiteto ou pelos museógrafos; da recepção ao bloco de exposições desce ao subsolo por uma escada encaixada numa torre de concreto, atravessa a galeria subterrânea que liga os dois prédios e chega ao eixo principal de circulação onde logo percebe a existência de mais dois outros corredores que o cruzam em ângulo agudo em pontos diferentes de modo a formar como que uma ilha triangular que impede a visão simultânea dos três eixos. São denominados os Eixo da Continuidade, Eixo do Exílio e Eixo do Holocausto.

A percepção simultânea de diferentes caminhos, enfatizada por linhas de luz no teto, permite a escolha do caminho a seguir, ao mesmo tempo em que causa uma leve desorientação à falta da costumeira referência de corredores que se cruzam em ângulo reto.

\section{O EIXO DA CONTINUIDADE}

O Eixo da Continuidade refere-se à continuidade da presença judia na Alemanha. É o maior dos três eixos, um comprido corredor reto continuado pela escada que liga o subsolo aos demais pavimentos, em cada patamar abrindo entrada para as salas de exposição permanente daquele nível. Porém acima do último patamar, oito degraus sem utilidade continuam a escada até topar com a parede do fundo. A continuidade portanto incorpora barreira, interrupção, mudança bruscas de direção e lacunas (Fig. 9,10,11e 12). 

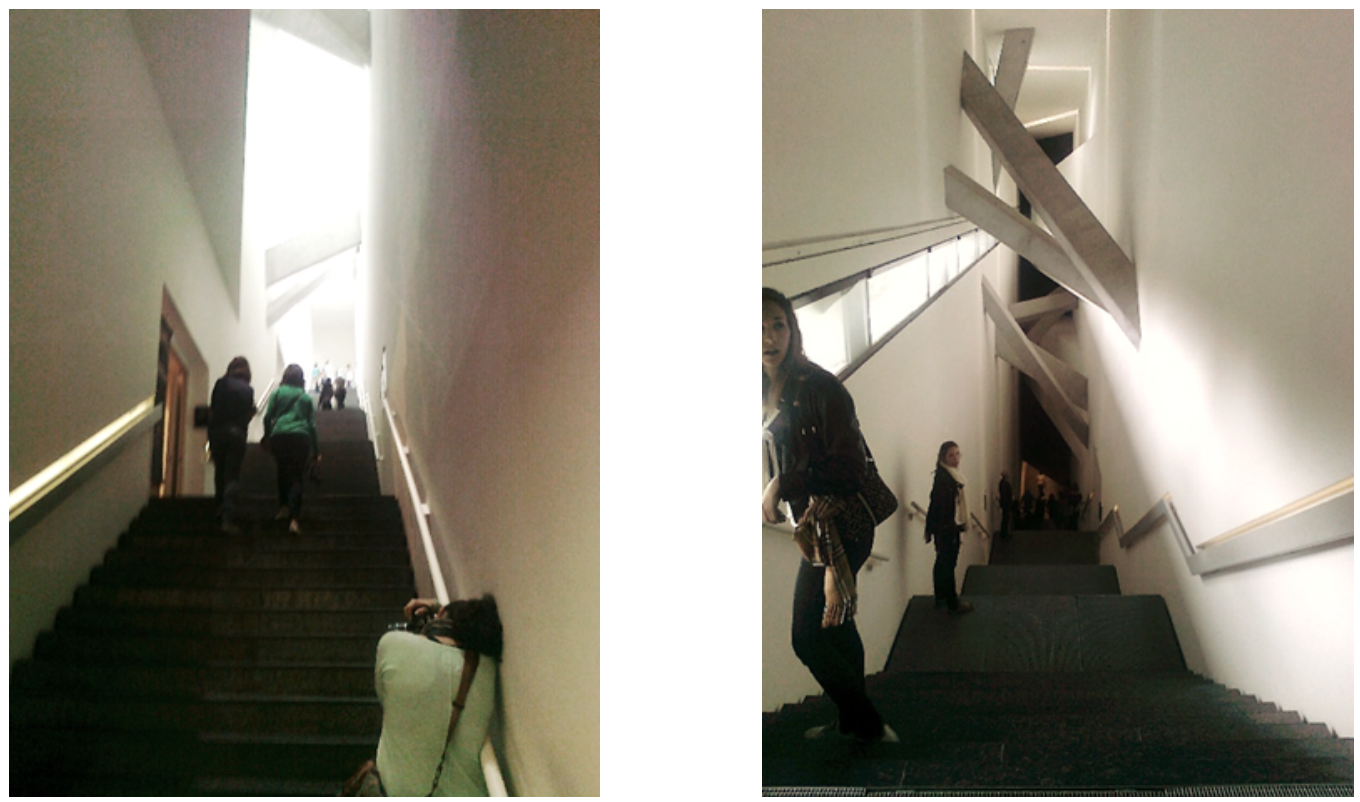

Fig. 9. Eixo da continuidade. No patamar, entrada para uma das salas de exposição.

Fig. 10: Eixo da continuidade visto do patamar mais alto.
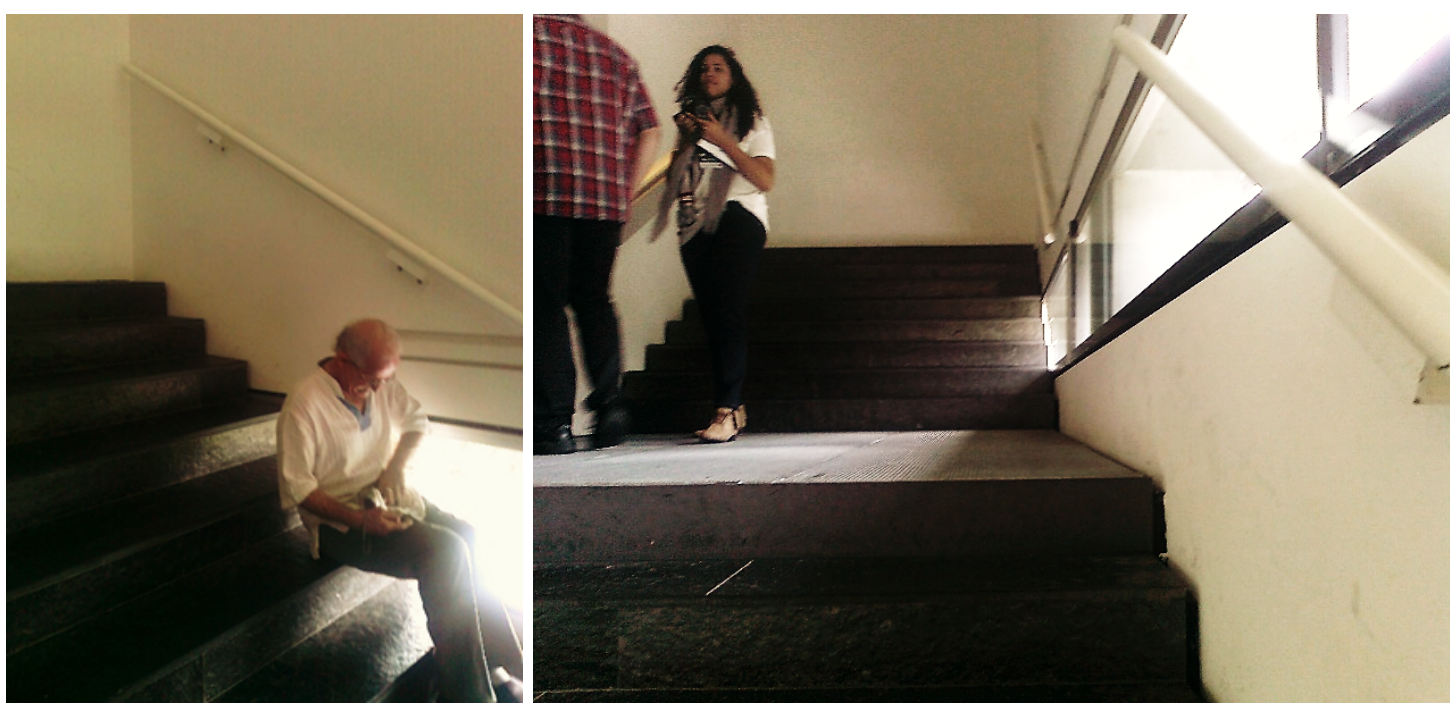

Fig. 11 e 12: Fim da escada do Eixo da Continuidade.

Fotos: Reinaldo Guedes Machado.

Nesse Eixo da Continuidade, reto e contínuo sob a linha quebrada dos pavimentos superiores, Libeskind implantou seis torres de concreto, prismas retos com bases poligonais irregulares, que atravessam toda a altura do prédio, destinadas a permanecerem vazias e, exceto o primeiro deles denominado Vazio da Memória, inacessíveis ao público sendo apenas percebidos por janelas e recorte nos andares superiores (Fig. 13). 


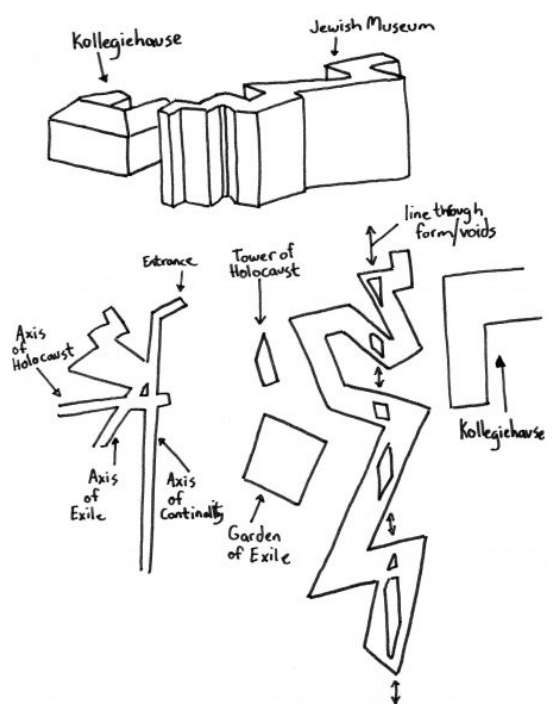

Fig.13: Croquis de Daniel Libeskind.

Fonte: http://arq-contemporanea-agcbb.blogspot.com.br/2011/06/museu-judaico-jewishmuseum.html

No Vazio da Memória, o piso é formado por milhares de rostos recortados em chapa de aço. Caminhar ali é inseguro, as rodelas de aço se acomodam umas ás outras sob a pressão dos passos produzindo um retinir metálico que reverbera nas paredes de concreto com o som de correntes, trilhos e maquinas. O lugar coloca o visitante onde estiveram as vítimas do nazismo, os faz reviver em parte sua angustia, sem reproduzir cenários, mas pela evocação do ambiente opressivo com os meios próprios da arquitetura: as dimensões geométricas do espaço, o material da construção, a luz e o som (Fig. 14,15,16 e 17).
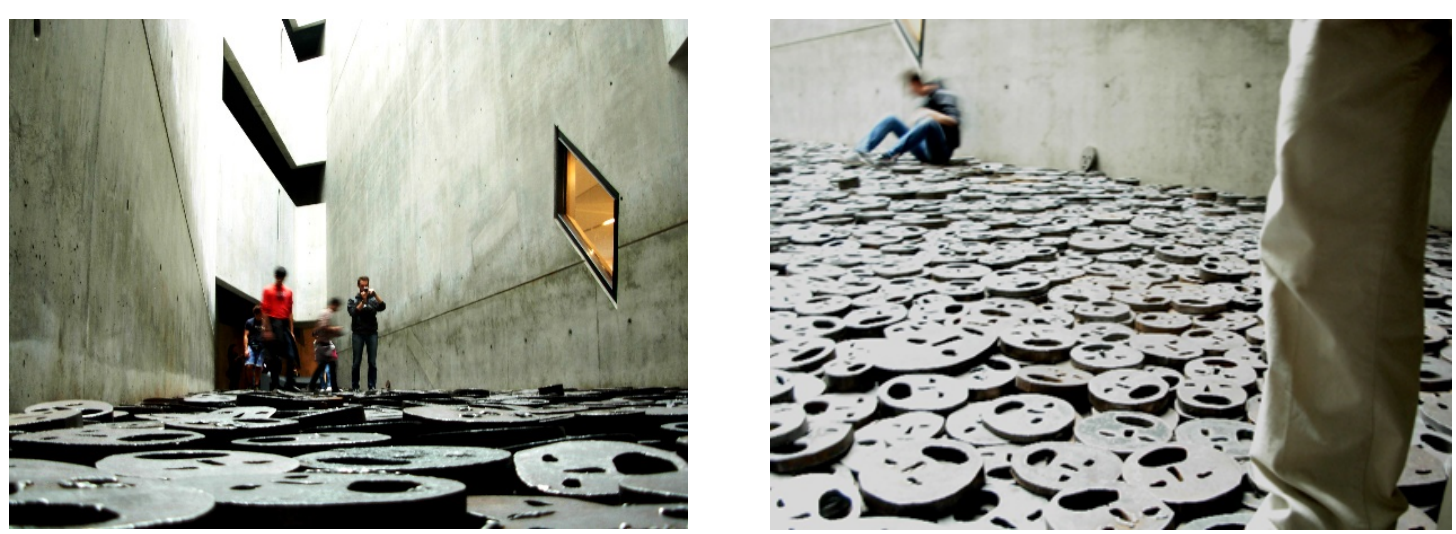

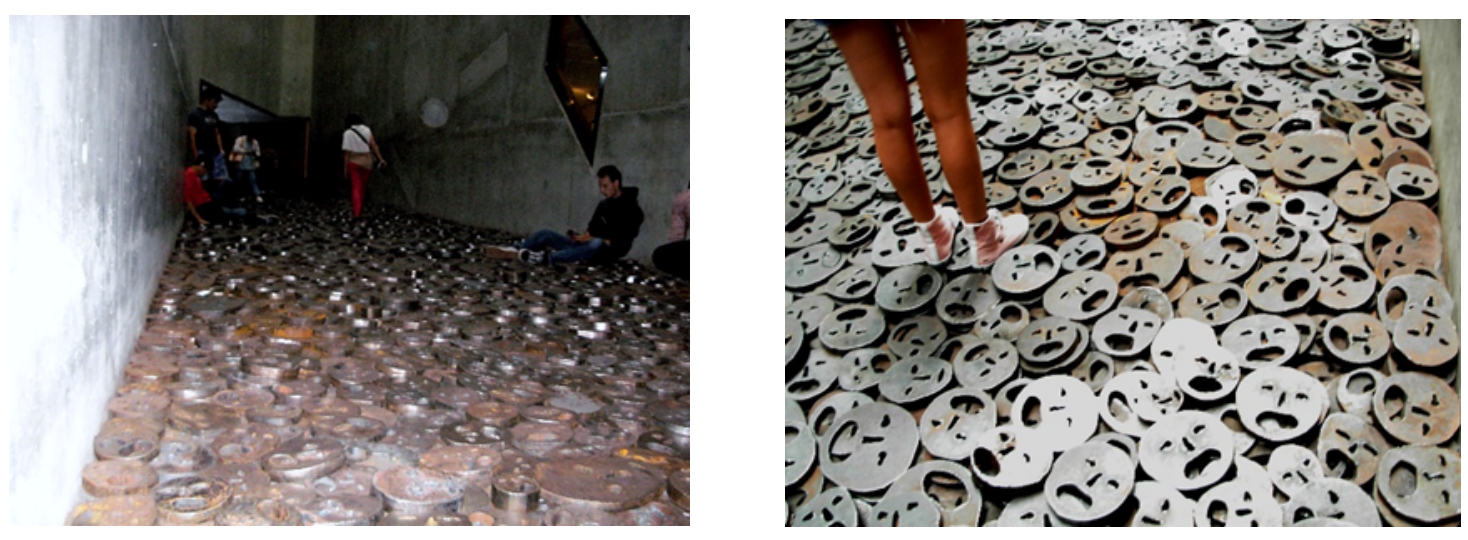

Fig. 14,15, 16 e 17 : Vazio da Memoria no Eixo da continuidade. Fotos: Reinaldo Gruedes Machado.

\section{O EIXO DO EXÍLIO}

O Eixo do Exilio é mais curto e, diferentemente do Eixo da Continuidade, tem finalidade expositiva; nas paredes laterais estão inscritos os nomes das cidades de destino e em vitrines se expõem fotografias documentando a vida dos emigrados. Conduz o visitante ao Jardim do Exílio que consiste num quadrado ocupado por 49 prismas retos de base quadrada, dispostos em malha regular fazendo um tabuleiro de pilares ocos cheios de terra no cimo dos quais estão plantadas oliveiras, comumente interpretadas como símbolo da paz.

Os pilares-vasos erguem-se perpendiculares ao plano do piso e como este é levemente inclinado, não há verticais no conjunto. São incompatíveis as informações percebidas pelo corpo: a visão a comunicar a ortogonalidade entre os pilares e o plano do chão induzindo a pensá-los como verticais e os orgãos do ouvido interno, bem como a distribuição das tensões musculares, a informar o desvio da vertical, produzindo como resultado uma leve vertigem ou ao menos um desconforto, e o caminhar inseguro dos visitantes entre os altos prismas de concreto.

Embora tendo sido a salvação de muitos, o Exilio não terá sido o retorno da ordem e da segurança na vida dos que fugiram. No Jardim do Exílio, rebaixado cerca de oito metros em relação ao nivel do terreno natural, não há saida senão voltar pelo mesmo caminho percorrido para chegar a ele; e se há nele luz natural, ar livre, a visão do céu e de espaçõs exteriores ao museu, nele também subsitem o enclausuramento, a 
inquietude e o sentimento de inadequação dos exilados nos novos ambientes onde se refugiarem (Fig. 18, 19,20 e 21).
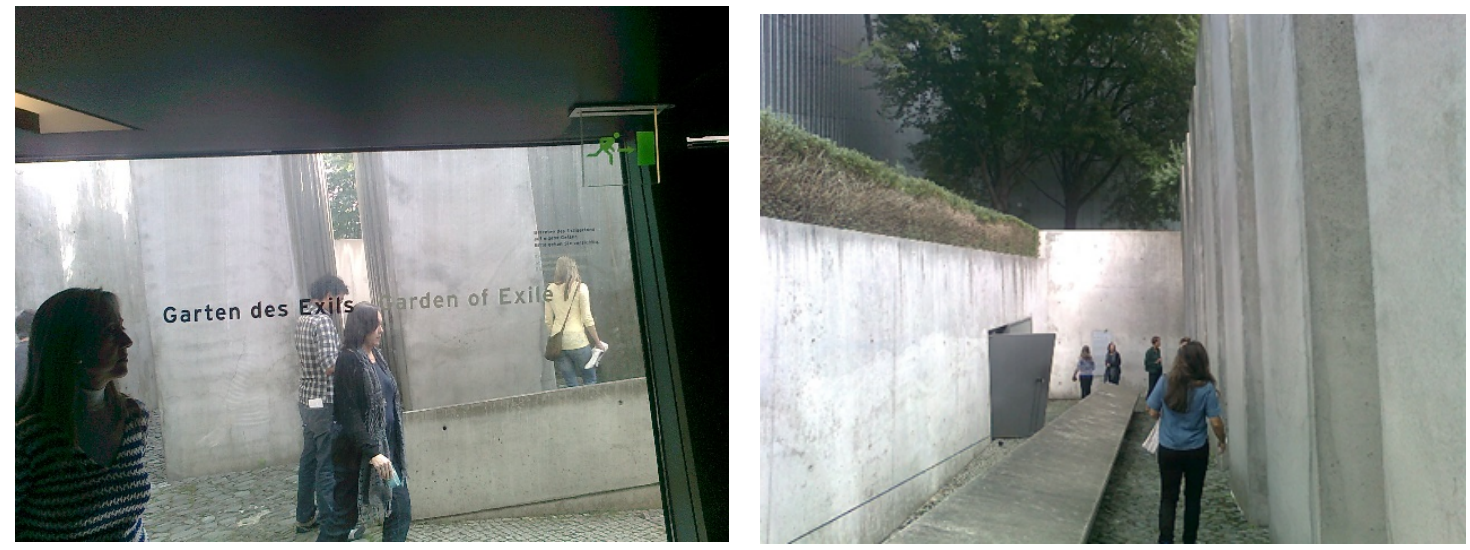

Fig. 18: Saída do Eixo do Exilio para o Jardim do Exílio

Fig. 19Visitantes caminham no Jardim do Exílio
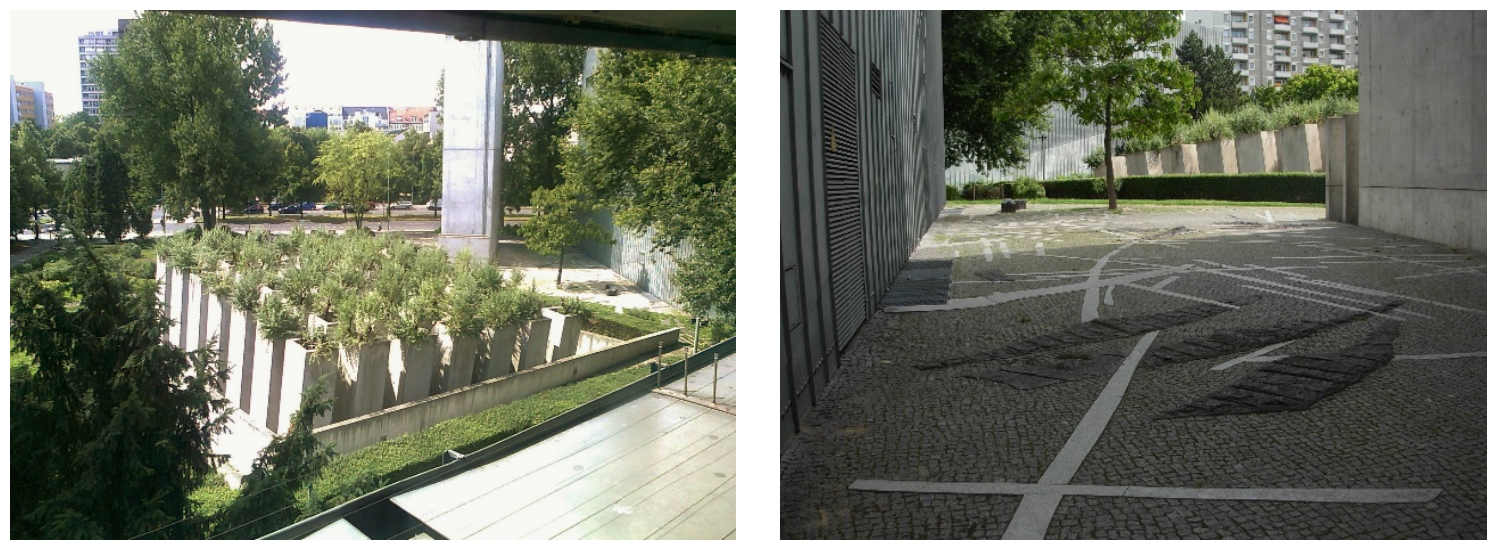

Fig. 20: Jardim do Exilio visto do Eixo da Continuidade.

Fonte: https://berlinabul.wordpress.com/2008/04/18/52/

Fig. 21: Topo do Jardim do Exílio visto da rua, por entre o prédio principal e a Torre do Holocausto. Fotos: Reinaldo Guedes Machado.

\section{EIXO DO HOLOCAUSTO}

O Eixo do Holocausto é também um espaço de circulação e de exposição. Nele, em vitrines numa das paredes laterais se expõem objetos comuns, sem nenhum interesse estético ou valor monetário tais como um dicionário usado, uma carta gravada em disco fonográfico, as agulhas usadas nos fonografos da época e outros parcos vestígios das 
pessoas desaparecidos no holocausto nazista. Esses objetos vulgares, sem importância intrinseca, parecem entretanto impregnadas da presença destas pessoas; são as raras provas materiais de que viveram um dia. Daí a importância e o impacto emocional que provocam talvez por repercutirem sobre os resquícios da crença animista recaldada que vê espíritos e poderes incorporados em objetos materiais.

Na parede oposta fica inscrita a longa lista dos campos de extermínio para onde foram deportados os judeu alemães.

O Eixo do Holocausto termina na Torre do Holocausto, outro prisma de concreto sem qualquer abertura nas paredes exceto a porta de acesso que se fecha automaticamente após a passagem do visitante, bloqueando a luz que vem do corredor. No teto, um rasgo estreito num canto é a única fonte de luz do ambiente. Uma escada de barras de ferro adossada a uma das paredes é interrompida pela lage do teto, a 22 metros de altura. Por ali também não há saída, a escada na parede é uma esperança falsa logo desmascarada.

A penumbra, o aspecto severo das paredes de concreto, a impossibilidade de fuga, o silêncio que impõe a gravidade do lugar transportam o visitante, sem reprodução cenografica ou mimetismo, a outra época quando outras pessoas viveram confinamento, sentiram-se impotentes, desamparadas e sem esperança. A arquitetura corporifica esta história e convoca o fantasma dessas vivências para que o visitante do museu as experimentem quer seja por reavivar os medos do escuro, do silêncio e do abandono remanescentes da infância, quer seja por empatia com as vítimas (Fig. 22, 23, 24 e 25).
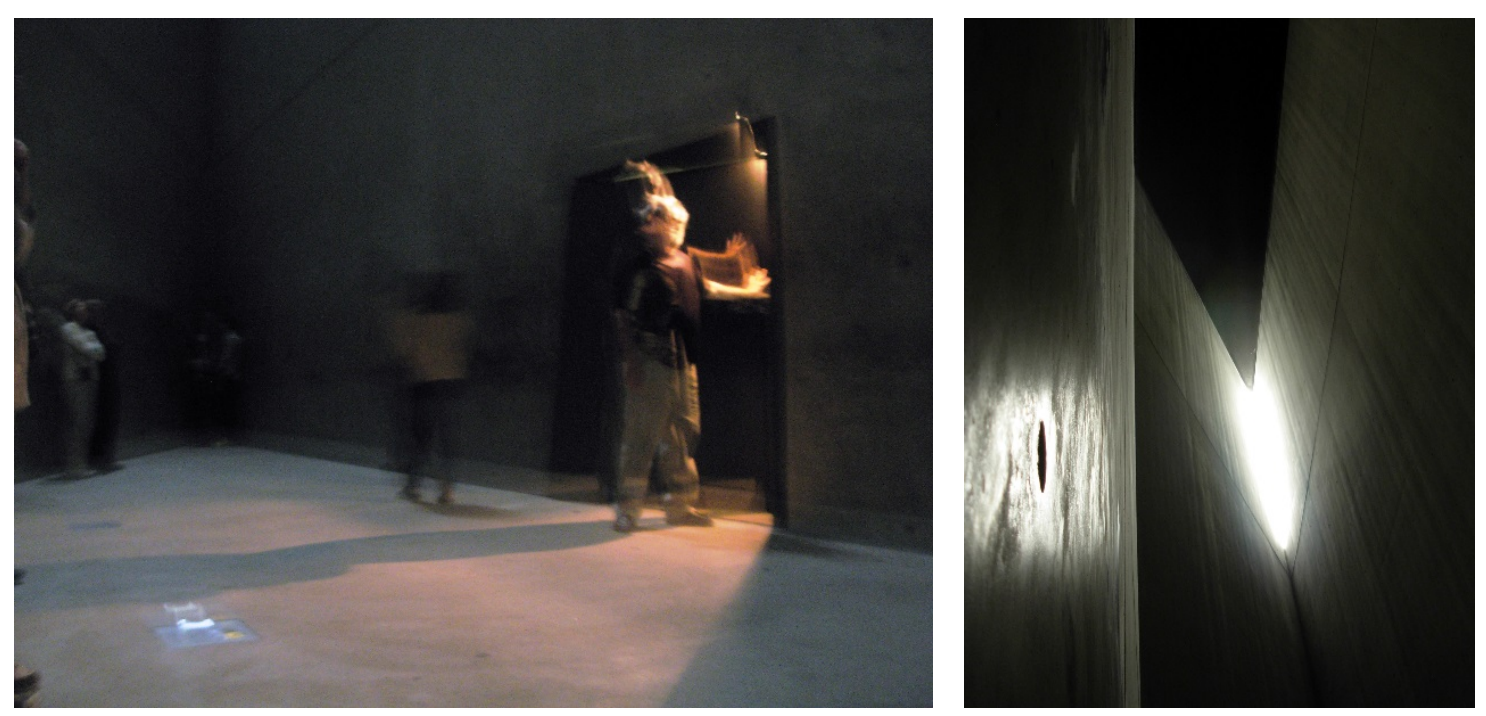

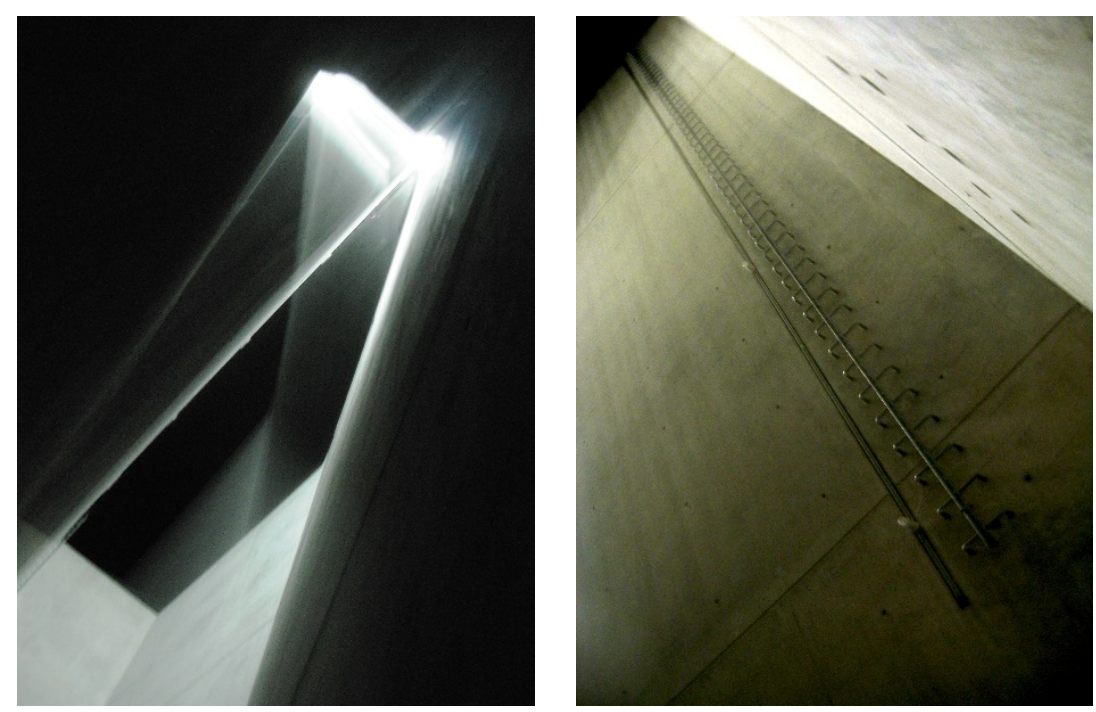

Fig. 22, 23, 24 e 25: Torre do Holocausto. Fotos: Alexandre Pereira Magalhães

\section{CONSIDERAÇÕES FINAIS}

Como se pode depreender da sucinta descrição contida neste texto, o Museu Judaíco de Berlim tem um carater discursivo, conceitual, mais pronunciado do que vemos na produção genérica da arquitetura atual.

Certo é que qualquer obra de arquitetura sempre revelará os valores éticos, políticos, as crenças e tudo o mais que constitui o pensamento do seu autor e de seus clientes. Mas nem sempre a expressão desses conteúdos é deliberadamente buscada; o mais comum é que pressões mais objetivas como as exigências de funcionalidade, do orçamento, de exequibilidade técnica dirigam, ou tenham peso maior, na concepção dos projetos.

Daniel Libeskind, sem descuidar do atendimento ás necessidades práticas de uso do edifício, declara constantemente em entrevistas e palestras ter tomado decisões de projeto por razões de natureza conceitual, filosófica. Por exemplo: ele concebe a história dos judeus na Alemanha como um fluxo contínuo, porém subterrâneo, de participação na construção da cultura da nação alemã, como um todo, ao mesmo tempo que preserva suas particularidades etnicas. Daí resulta esta casamata de concreto revestida de zinco, com poucas aberturas a impedir a visão do exterior para dentro e a produzir uma distibuição irregular de luzes e sombras, mistérios e confinamentos. Daí também a decisão de atravessar o prédio da Suprema Corte pela torre de concreto que conduz ao subsolo onde instalou os principais eixos de circulação. 
É ilustrativo dessa atitude o depoimento em que o arquiteto relata sua dificuldade em convencer o Senado de Berlim a arcar com o custo dos "vazios" que pontuam o Eixo da Continuidade e as salas de exposição dos andares superiores. Diz Libeskind:

\begin{abstract}
Tentei convencê-los todo o tempo de que aquilo era importante, de que aquele era um museu necessário agora. Ali, o que se pretendia era contar uma história que não dava simplesmente para colocar dentro do espaço de um museu convencional e dizer: sim, agora está tudo acabado, não há mais nada a dizer, está tudo no museu, o assunto morreu, vamos procurar outras coisas novas para fazer.
\end{abstract}

\begin{abstract}
Não. Este é um edifício que, para sempre, eternamente, deverá estimular a atenção das pessoas para a diferença entre a substância daquela história que pode ser contada e daquela que jamais poderá ser; daquilo que nela poderá apenas ser intuído; daquilo que sempre nela permanecerá subvertido e que qualquer tentativa de controle resultará em que essa história seja equivocadamente dada como terminada. Acredito ser esse o grande desafio do prédio do Museu Judaico de Berlim.( LIBESKIND, 2000) ${ }^{6}$
\end{abstract}

$\mathrm{Na}$ arquitetura, como mostra Libeskind, diferentemente da linguagem verbal, os conceitos precisam ser expressos por meio sensíveis, espaços reais, paredes, passagens e impedimentos reais, e pelas vivências que propiciam aos usuários do prédio.

Há alguma semelhança entre os espaços de plantas irregulares, os jogos de luz do museu de Berlim e a cenografia dos filmes expressionista. Não se veja aqui uma influência direta, Libeskind não os menciona, nem a Freud, em suas palestras recheiadas de citações de literatura. ${ }^{7}$

Mas ali estão presentes os mesmos recursos plasticos do expressionismo; entre eles, a recusa do ângulo reto como ordenador dos espaços; a recusa da luminosidade excessiva distribuida uniformemente, comodos inacessíveis, pés direitos variaveis ao longo dos corredores de pisos levemente inclinados provocando, por meios artísticos, alguns dos processos psiquicos que Freud estudou como cientista.

Se não cabe apontar filiação ou influência dos antecessores, cabe entretanto reconhecer a consideração do inquietante como categoria estética e sua exploração sem apelo sensacionalista.

6 LIBESKIND, Daniel. Depoimento. In NEUMANN, Stan e COPANS, Richard. Le mueée Juif de Berlin - Entre les lignes. Paris: Le Centre George Pompidou, 2000.

7 Architecture is a Language: Daniel Libeskind at TEDxDUBLIN. [em 08/09/2012] Disponível em< https://www.youtube.com/watch?v=yEkDosanxGk> 
O Museu Judaíco de Berlim é um prédio de alto significado simbólico não só pelo material que expõe, mas como objeto arquitetonico capaz de comunicar a visão de seu autor sobre a continuidade da cultura judia e os acontecimentos dramáticos do exílio forçado e da morte durante o período nazista. Trezentos e cinquenta mil pessoas o visitaram em dois anos, ainda vazio ${ }^{8}$. Hoje, dotado de uma acervo de quatro mil objetos, recebe cerca de setecentos e cinquenta mil visitantes/ano. Ao que tudo indica, Libeskind conseguiu vencer o desafio que se propusera ao pensar o edifício.

\section{REFERÊNCIAS BIBLIOGRÁFICAS}

FREUD, Sigmund. $O$ 'estranho'. Trad. de Eudoro Augusto Maciel da Silveira. In Uma neurose infantil e outros trabalhos (1917-1918). Edição Standard Brasileira das Obras Psicológicas Completas, Volume XVII. Rio de Janeiro: Imago, 1996.

. (1919) O Inquietante. Obras completas. Trad. de: Paulo César de Souza. São Paulo: Companhia das Letras, 2010.

LIBESKIND, Daniel. Architecture is a Language: Daniel Libeskind at TEDxDUBLIN. [em 08/09/2012]

Disponível em< https://www.youtube.com/watch?v=yEkDosanxGk>

MACHADO, Marisa F. Museu Judaico de Berlim - Daniel Libeskind.

Disponível em <https://fauforma2.files.wordpress.com/2009/08/libeskind_museujudaico-de-berlim.pdf $>$

NEUMANN, Stan e COPANS, Richard. Le mueée Juif de Berlin - Entre les lignes. Paris: Le Centre George Pompidou, 2000.

WIENNE, Robert. Das Cabinet des Dr. Caligari, Berlim: DECLA Film Gesellchaft, 1920. Disponível em https://www.youtube.com/watch?v=AP3WDQXkJq4

8 NEUMANN, Stan e COPANS, Richard. Le mueée Juif de Berlin - Entre les lignes. Paris: Le Centre George Pompidou, 2000. 